Original Article

\title{
Relationship of body composition, knee extensor strength, and standing balance to lumbar bone mineral density in postmenopausal females
}

\author{
Seungsub Shin, PT, PhD ${ }^{1)}$, Kyeonguin Lee, PT, PhD ${ }^{1)}$, Changho Song, PT, $\mathrm{PhD}^{1)^{*}}$ \\ 1) Department of Physical Therapy, College of Health Science, Sahmyook University: \\ 26-21 Gongneung2-dong, Nowon-gu, Seoul 139-742, Republic of Korea
}

\begin{abstract}
Purpose] This study aimed to investigate correlations between lumbar bone mineral density (BMD) and general characteristics of postmenopausal females, including body composition, knee extensor strength, standing balance, and femur BMD. [Subjects and Methods] A total of 40 postmenopausal females (55.6 \pm 4.6 years) who were caregivers or guardians of patients in the $\mathrm{K}$ hospital were included in the study. The weight, height, body composition, left and right knee extensor strength, standing balance, femur BMD, and lumbar BMD measurements of the subjects were obtained. [Results] The effect of measurement variables on lumbar BMD was examined. Increases in age and menopausal duration were observed to significantly increase lumbar BMD, whereas an increase in height was found to significantly decrease lumbar BMD. An increase in soft lean mass, skeletal muscle mass, fat-free mass, and femur BMD was also associated with significantly decreased lumbar BMD. [Conclusion] Age, menopausal duration, soft lean mass, skeletal muscle mass, and fat-free mass were factors that decreased lumbar BMD in menopausal females. This study is expected to provide basic knowledge for osteoporosis prevention and treatment programs for postmenopausal females.

Key words: Postmenopausal females, Body composition, Bone mineral density
\end{abstract}

(This article was submitted Feb. 16, 2016, and was accepted Apr. 7, 2016)

\section{INTRODUCTION}

Osteoporosis has become an important issue that affects the health and decreases the quality of life of elderly females because they have a longer average life expectancy than men ${ }^{1)}$. This systemic disease causes frequent fractures, followed by weakening of bone strength ${ }^{2,3)}$. Osteoporosis itself has no symptoms, but it increases the fracture risk of body parts by decreasing bone mineral density (BMD) in the femur, spine, wrist, and other skeletal sites and eventually causes collapse of bone structure ${ }^{4,5}$.

A recent study has suggested that among lumbar BMD-related factors, age, weight, pulse rate, and glycated hemoglobin (HbA1c) level can predict lumbar BMD in premenopausal females, with weight being the most influential predictive factor ${ }^{6}$. The same study pointed out that age, weight, and uric acid levels can predict lumbar BMD in postmenopausal females, with age as a particularly important predictive factor ${ }^{6}$. Previous studies reported that an annual weight increase of about $0.8 \mathrm{~kg}$ for postmenopausal females is due to an increase in body fat mass, followed by changes in hormones after menopause ${ }^{7}$. Moreover, BMD in postmenopausal females is closely related to weight, body fat mass, and fat-free mass because increased weight causes stress to the skeletal system and results in an increase in bone mass, which leads to enhanced cellular activity in bone formation ${ }^{7}$. A contrasting result was also reported, in which lumbar BMD and femur BMD in premenopausal females presented a significant positive correlation with fat-free mass, and lumbar and femur BMD in postmenopausal females presented a positive correlation with body fat mass ${ }^{8)}$. In general, fat-free mass and weight increase in premenopausal females because of aging; fat-free mass decreases and body fat mass increases in postmenopausal females ${ }^{9}$. Thus, the BMD

\footnotetext{
*Corresponding author. Changho Song (E-mail: chsong@syu.ac.kr)

(C)2016 The Society of Physical Therapy Science. Published by IPEC Inc.

This is an open-access article distributed under the terms of the Creative Commons Attribution Non-Commercial No Derivatives (by-nc-nd) License $<$ http://creativecommons.org/licenses/by-nc-nd/4.0/>.
} 
in premenopausal females present a significant positive correlation with fat-free mass, and the BMD of postmenopausal females present a significant positive correlation with body fat mass ${ }^{7,10)}$. However, Reid, et al. ${ }^{11)}$ reported that the BMD in premenopausal females is significantly correlated with body fat mass and fat-free mass. In a BMD correlation study of 50 postmenopausal females, bone mineral content was shown to correlate significantly with fat-free mass rather than with body fat mass ${ }^{12)}$. Previous studies presented contrasting results for correlation between body fat mass, fat-free mass, and BMD in females. This result was obtained probably because the groups were assigned based on age or menopause stage, regardless of varying heterogeneity in subject, age, measured part, and measurement device, among others ${ }^{13)}$.

Bone mineral content in adults decreases about $1 \%$ annually after the age of 30 , along with an average muscle mass decrease from $0.4 \mathrm{~kg}$ to $0.8 \mathrm{~kg}$ every 10 years after age 20 and from $10-25 \%$ decreases after age $50^{14,15)}$. Muscle strength and BMD are highly correlated, with a particularly strong positive correlation in postmenopausal females, because the musculoskeletal system is a structure resistant to external load ${ }^{16-19}$. In a study that measured the maximum extensor strength of left and right lower limbs and BMD in 71 females over the age of 35, the BMD and muscle strength of premenopausal females were significantly higher than those of postmenopausal females ${ }^{20}$. However, the correlation between BMD and knee extensor strength was significant only in premenopausal females and no correlation was found in postmenopausal females ${ }^{20}$. Other previous studies also reported that a positive correlation between actual muscle strength and BMD is unclear because correlation between muscle strength and BMD is easily influenced by confounding variables ${ }^{13,21,22)}$.

Therefore, the aim of this study was to investigate correlations between lumbar BMD and general characteristics of postmenopausal females, body composition, knee extensor strength, standing balance, and femur BMD.

\section{SUBJECTS AND METHODS}

Postmenopausal females who were caregivers or guardians of patients in the K hospital were included in the study. The inclusion criteria consisted of postmenopausal females whose last menstrual period had occurred more than one year ago, who had not taken osteoporosis-related drugs or hormones in the last six months, who had no history of fracture in the lumbar or femur, and who had not participated in muscle strengthening exercises that could influence BMD in the last six months. The exclusion criteria were onset of menopause before age 40, menopause followed by hysterectomy or oophorectomy, current smoker or intake of two or more alcoholic drinks per day, presence of hormonal disorders or other chronic diseases, females with history of malignant tumor, and females with lumbar-related disease or chronic musculoskeletal disorder.

The Institutional Review Board of Sahmyook University approved all protocols and procedures, and all 40 subjects signed a statement of informed consent.

The measurements of body composition, left and right knee extensor strength, standing balance, and lumbar and femur BMD of the subjects were obtained. The change in the body composition of subjects was examined by conducting measurement with InBody (InBody 720, Biospace, Korea). InBody provides various information on body composition by measuring biological electric impedance, using 4 pole 8-point touch electrodes. This measurement assists in diagnosing obesity, assessing nutrition, and managing weight. Food intake of subjects was restricted $30 \mathrm{~min}$ before the test. The subjects were also instructed to empty their bladders and bowels $30 \mathrm{~min}$ prior to the test. Measurements were conducted in light clothing under comfortable and stable conditions. Subjects were instructed to step on electrodes barefoot, hold hand electrodes lightly, and stand with both arms slightly apart.

A manual muscle tester (Model 01163; Lafayette, USA) was used to measure left and right knee extensor strength of subjects. Knee extensor strength was measured with subjects sitting upright while leg extended and pressure applied by the foot to the equipment pressure plate. The inspector then applied manual pressure to the leg while the subject applied counterpressure for $7 \mathrm{~s}$. The measurement was taken three times with $1 \mathrm{~min}$ of rest following each test. Knee extensor strength was defined as the mean value of these three tests.

A force plate (PDM Multifunction Force Measuring Plate; Zebris, Germany) was used to measure standing balance. The inspector performed the test with the subjects' eyes open and closed. To measure standing balance with eyes open, subjects were instructed to step up to the force plate barefoot, with arms comfortably next to the body, and gaze at a red circle of $3 \mathrm{~cm}$ in diameter. This measurement was performed $3 \mathrm{~m}$ away at eye level. Standing balance was measured for $30 \mathrm{~s}$ while the subjects gazed at the red circle. The mean postural sway was recorded three times. To measure standing balance with eyes closed, subjects were in the same posture as with eyes open, and standing balance was measured for $30 \mathrm{~s}$. The mean postural sway was again measured three times.

BMD of lumbar vertebrae 2, 3, and 4 and the left femoral neck were measured. The right femoral neck was measured in cases of femoral arthroplasty or unavailability of the left femoral neck. The dual-energy X-ray absorptiometry (DEXA) is considered the gold standard of BMD measurement and presents high reliability and validity. DEXA was highly correlated with BMD measurement $(r=0.899, \mathrm{p}<0.001)$. Z- and T-scores were used as the measurement value of BMD. Z-score is obtained by subtracting the mean BMD of subjects of the same age from the measured BMD and dividing it by the BMD standard deviation of subjects of the same age. T-score was calculated by subtracting the mean BMD of young females age 20-30 from the measured BMD and dividing it by the BMD standard deviation of young females aged 20-30.

All statistical analyses for this study were performed with SPSS version 19.0. The Shapiro-Wilk test was conducted to evaluate the normality of variables. Descriptive statistics was used for general characteristics of subjects. The correlation 
between lumbar BMD and measurement values of subjects was examined by performing Pearson's correlation test. Odds ratio of logistic regression analysis was also applied to examine the influence of high and low lumbar BMD on variables. $\mathrm{P}<0.05$ was considered statistically significant.

\section{RESULTS}

Correlations between lumbar BMD and general characteristics of subjects, body composition, knee extensor strength, standing balance, and femur BMD are presented in Table 1. Table 2 and Fig. 1 show the influence of general characteristics, body composition, knee extensor strength, standing balance, and femur BMD on lumbar BMD.

Table 1. Correlations between lumbar BMD and measure variables

\begin{tabular}{|c|c|c|c|c|c|c|c|c|}
\hline \multirow{2}{*}{$\begin{array}{l}\text { Variables } \\
\text { General characteristics }\end{array}$} & \multicolumn{2}{|c|}{ Mean (SD) } & \multicolumn{2}{|c|}{ Lumbar BMD } & \multicolumn{2}{|c|}{ Lumbar T-score } & \multicolumn{2}{|c|}{ Lumbar Z-score } \\
\hline & & & & & & & & \\
\hline Age (years) & 55.6 & (4.6) & -0.5 & $* *$ & -0.5 & $* *$ & -0.3 & \\
\hline Height (cm) & 158.2 & $(4.5)$ & 0.4 & $*$ & 0.4 & $*$ & 0.4 & $*$ \\
\hline Weight (kg) & 60.2 & $(7.7)$ & 0.4 & ${ }^{* *}$ & 0.4 & * & 0.4 & $* *$ \\
\hline Menopausal period (years) & 7.7 & $(4.4)$ & -0.5 & $* *$ & -0.5 & $* *$ & -0.3 & \\
\hline \multicolumn{9}{|l|}{ Body composition } \\
\hline Soft lean mass (kg) & 39.3 & $(3.7)$ & 0.6 & $* *$ & 0.6 & $* *$ & 0.6 & $* *$ \\
\hline Skeletal muscle mass $(\mathrm{kg})$ & 22.4 & $(2.3)$ & 0.6 & $* *$ & 0.5 & $* *$ & 0.5 & $* *$ \\
\hline Fat-free mass $(\mathrm{kg})$ & 41.6 & $(3.9)$ & 0.6 & $* *$ & 0.6 & $* *$ & 0.6 & $* *$ \\
\hline Body fat mass (kg) & 18.6 & $(5.2)$ & 0.2 & & 0.1 & & 0.2 & \\
\hline Percent body fat (\%) & 30.5 & (5.3) & -0.0 & & -0.1 & & -0.1 & \\
\hline Waist-hip ratio (\%) & 89.8 & $(0.0)$ & -0.1 & & -0.1 & & -0.0 & \\
\hline Body mass index $\left(\mathrm{kg} / \mathrm{m}^{2}\right)$ & 24.5 & $(3.8)$ & 0.3 & & 0.2 & & 0.3 & \\
\hline \multicolumn{9}{|l|}{ Knee extensor strength } \\
\hline Right (kg) & 20.3 & $(3.0)$ & 0.2 & & 0.2 & & 0.2 & \\
\hline Left $(\mathrm{kg})$ & 18.0 & $(3.2)$ & 0.1 & & 0.1 & & 0.1 & \\
\hline \multicolumn{9}{|l|}{ Standing balance } \\
\hline Eye open - postural sway $(\mathrm{cm})$ & 55.3 & $(11.5)$ & -0.1 & & -0.1 & & -0.1 & \\
\hline Eye closed - postural sway (cm) & 63.5 & $(11.9)$ & -0.1 & & -0.1 & & -0.2 & \\
\hline \multicolumn{9}{|l|}{ Femur BMD } \\
\hline T-score & -1.3 & $(0.9)$ & 0.7 & $* *$ & 0.7 & $* *$ & 0.7 & $* *$ \\
\hline Z-score & -0.5 & $(0.7)$ & 0.6 & $* *$ & 0.7 & $* *$ & 0.7 & $* *$ \\
\hline
\end{tabular}

SD: standard deviation; BMD: bone mineral density. $* \mathrm{p}<0.05, * * \mathrm{p}<0.01$

Table 2. Influence of measure variables on lumbar BMD

\begin{tabular}{lrrrr}
\hline Variables & B & SE & OR & \\
\hline General characteristics & & & & \\
$\quad$ Age & 0.3 & 0.1 & 1.3 & ${ }^{* *}$ \\
Height & -0.2 & 0.1 & 0.8 & $*$ \\
Weight & -0.1 & 0.0 & 0.2 & \\
$\quad$ Menopausal period & 0.3 & 0.1 & 1.3 & $*$ \\
Body composition & & & & \\
$\quad$ Soft lean mass & -0.3 & 0.1 & 0.8 & $*$ \\
$\quad$ Skeletal muscle mass & -0.4 & 0.2 & 0.6 & $*$ \\
$\quad$ Fat-free mass & -0.3 & 0.1 & 0.8 & $*$ \\
Femur BMD & & & & \\
$\quad$ T-score & -1.4 & 0.5 & 0.2 & $*$ \\
$\quad$ Z-score & -1.1 & 0.5 & 0.3 & $*$ \\
\hline
\end{tabular}

BMD: bone mineral density; B: logistic regression coefficient; SE: standard error; OR: odds ratio.

$* \mathrm{p}<0.05, * * \mathrm{p}<0.01$

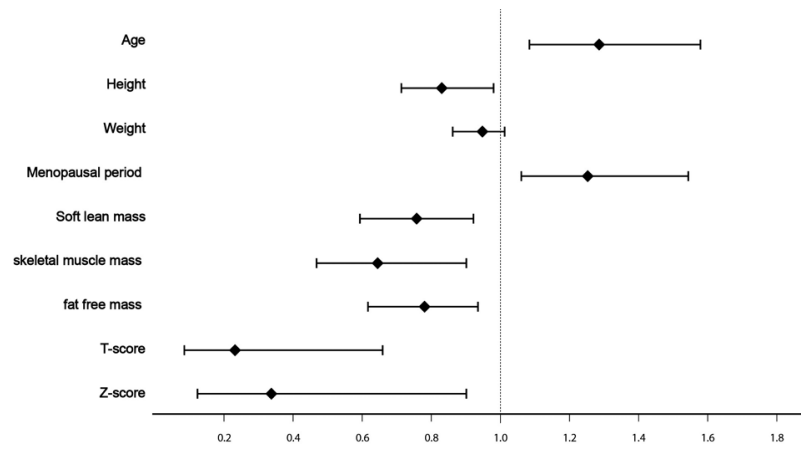

Fig. 1. Odds ratio for influence of measure variables on lumbar BMD 


\section{DISCUSSION}

This study was conducted to analyze the correlation between lumbar BMD and general characteristics, body composition, knee extensor strength, standing balance, and femur BMD in 40 postmenopausal females. The lumbar BMD of subjects was strongly negatively correlated with age and menopausal duration, whereas positively correlated with height and weight. Previous studies suggested that age is the most predictive and influential risk factor of lumbar BMD because a remarkable decrease in BMD occurs after menopause ${ }^{6}$. . BMD and weight presented strong positive correlations in the results obtained by another study, which was conducted with 220 females aged over 35 years ${ }^{23}$. The result of the present research agrees well with those in previous studies.

Soft lean mass, skeletal muscle mass, and fat-free mass of the subjects indicated a strong positive correlation with lumbar BMD. No significant correlation was found for body fat mass, percent body fat, waist-hip ratio, and body mass index.

The femur BMD of the subjects was significantly positively correlated with lumbar BMD. In a BMD study with 885 perimenopausal and postmenopausal females, lumbar BMD presented a strong positive correlation with femur BMD ${ }^{24)}$. Based on 'Mechanostat' theory of synthesis and absorption, a direct influence on bone is observed with an increase in impact ${ }^{25}, 26$ ). Therefore, BMD differs accordingly to the degree of impact and part. In a study with tennis players who exercised more than $3 \mathrm{~h}$ /week for 25 years or more, significant difference was not found in lumbar or femur neck BMD, although the BMD of the frequently used arm was higher than that of the less used $\mathrm{arm}^{27}$. In a study with 55 general female office workers and 44 nurses with more than 5 years of experience, no significant difference was observed in lumbar BMD; however, the femur BMD of general female officer workers who spend a considerable amount of time sitting was significantly lower than that of nurses ${ }^{28)}$. A significant correlation was found between lumbar and femur BMD because the subjects of the two groups were mostly caregivers who looked after patients in the hospital most of the time, and performed similar physical activities. To examine the influence of change in age, height, weight, and menopausal duration of subjects on lumbar BMD, logistic regression analysis was conducted with high and low lumbar BMD based on normal variables. The analysis revealed that there are 1.318 and 1.284 times increases in the probability of inclusion into the low lumbar BMD group, with a one-year increase in age and menopausal duration. With regard to height, a 1.190 times increase was found in the probability of inclusion into the normal group with a $1 \mathrm{~cm}$-increase in height ${ }^{6}$. Weight did not significantly influence lumbar BMD. Given the remarkable decrease in BMD after menopause, previous studies reported that age are the most predictive and influential risk factor of lumbar BMD. The present study revealed that menopausal duration and age are the predictive factors of BMD risk.

Logistic regression analysis was also applied to examine the influence of body composition of subjects on lumbar BMD. The results revealed a 1.333 times increase in the probability of inclusion into the high group of normal lumbar BMD range with a $1 \mathrm{~kg}$ increase in muscle mass. There was a 1.533 times increase in the probability of inclusion into the high group of normal lumbar BMD range with a $1 \mathrm{~kg}$ increase in skeletal muscle mass. Moreover, a 1.308 times increase was found in the probability of inclusion into the high group of normal lumbar BMD range, with a $1 \mathrm{~kg}$ increases in fat-free mass. No significant influence on lumbar BMD was found for body fat mass, percent body fat, waist-hip ratio, and body mass index. A previous study with 261 postmenopausal females reported that body fat mass or percent body fat is not significantly correlated with lumbar or femur $\mathrm{BMD}^{29}$. In a study that examined the correlation between body composition and BMD in 3,241 perimenopausal and postmenopausal females in Germany, fat-free mass rather than body fat mass presents a significant correlation with lumbar BMD. Thus, the influence of soft lean mass, skeletal muscle mass, and fat-free mass on lumbar BMD is significant, as revealed in the logistic regression analysis in the present study ${ }^{30}$.

In conclusion, age, menopausal duration, soft lean mass, skeletal muscle mass, and fat-free mass are factors that influenced lumbar BMD risk in postmenopausal females. This study is expected to provide basic knowledge for osteoporosis prevention and treatment programs for postmenopausal females.

\section{REFERENCES}

1) Jun HJ, Kim KJ, Lee JS, et al.: Association between osteoporotic fractures and quality of life based on the Korean Community Health Survey of 2010. J Phys Ther Sci, 2015, 27: 3325-3328. [Medline] [CrossRef]

2) Siris ES, Miller PD, Barrett-Connor E, et al.: Identification and fracture outcomes of undiagnosed low bone mineral density in postmenopausal women: results from the National Osteoporosis Risk Assessment. JAMA, 2001, 286: 2815-2822. [Medline] [CrossRef]

3) Tanaka R, Ozawa J, Umehara T, et al.: Does exercise intervention improve muscle strength and balance of Japanese subjects with osteoporosis?: a systematic review and meta-analysis of randomized controlled trials. J Phys Ther Sci, 2013, 25: 397-401. [CrossRef]

4) Korkmaz N, Tutoğlu A, Korkmaz I, et al.: The relationships among vitamin D level, balance, muscle strength, and quality of life in postmenopausal patients with osteoporosis. J Phys Ther Sci, 2014, 26: 1521-1526. [Medline] [CrossRef]

5) Tanaka R, Ozawa J, Umehara T, et al.: Exercise intervention to improve the bone mineral density and bone metabolic markers as risk factors for fracture in Japanese subjects with osteoporosis: a systematic review and meta-analysis of randomized controlled trials. J Phys Ther Sci, 2012, 24: 1349-1353. [CrossRef]

6) Choi S, Hwang D, Song H, et al.: The predictors of lumbar spinal bone mineral density in pre-and postmenopausal women. J Korean Soc Menopause, 2009, 15: 101-109.

7) Slemenda CW, Hui SL, Williams CJ, et al.: Bone mass and anthropometric measurements in adult females. Bone Miner, 1990, 11: 101-109. [Medline] [Cross- 
Ref]

8) Cui LH, Shin MH, Kweon SS, et al.: Relative contribution of body composition to bone mineral density at different sites in men and women of South Korea. J Bone Miner Metab, 2007, 25: 165-171. [Medline] [CrossRef]

9) Maltais ML, Desroches J, Dionne IJ: Changes in muscle mass and strength after menopause. J Musculoskelet Neuronal Interact, 2009, 9: 186-197. [Medline]

10) Ijuin M, Douchi T, Matsuo T, et al.: Difference in the effects of body composition on bone mineral density between pre- and postmenopausal women. Maturitas, 2002, 43: 239-244. [Medline] [CrossRef]

11) Reid IR, Plank LD, Evans MC: Fat mass is an important determinant of whole body bone density in premenopausal women but not in men. J Clin Endocrinol Metab, 1992, 75: 779-782. [Medline]

12) Chen Z, Lohman TG, Stini WA, et al.: Fat or lean tissue mass: which one is the major determinant of bone mineral mass in healthy postmenopausal women? J Bone Miner Res, 1997, 12: 144-151. [Medline] [CrossRef]

13) Bayramoğlu M, Sözay S, Karataş M, et al.: Relationships between muscle strength and bone mineral density of three body regions in sedentary postmenopausal women. Rheumatol Int, 2005, 25: 513-517. [Medline] [CrossRef]

14) Gallagher D, Visser M, De Meersman RE, et al.: Appendicular skeletal muscle mass: effects of age, gender, and ethnicity. J Appl Physiol 1985, 1997, 83: 229-239. [Medline]

15) Roubenoff R, Hughes VA: Sarcopenia: current concepts. J Gerontol A Biol Sci Med Sci, 2000, 55: M716-M724. [Medline] [CrossRef]

16) Lima RM, Bezerra LM, Rabelo HT, et al.: Fat-free mass, strength, and sarcopenia are related to bone mineral density in older women. J Clin Densitom, 2009, 12: 35-41. [Medline] [CrossRef]

17) Nguyen T, Sambrook P, Kelly P, et al.: Prediction of osteoporotic fractures by postural instability and bone density. BMJ, 1993, 307: 1111-1115. [Medline] [CrossRef]

18) Ribom E, Ljunggren O, Piehl-Aulin K, et al.: Muscle strength correlates with total body bone mineral density in young women but not in men. Scand J Med Sci Sports, 2004, 14: 24-29. [Medline] [CrossRef]

19) Vuori I, Heinonen A, Sievänen H, et al.: Effects of unilateral strength training and detraining on bone mineral density and content in young women: a study of mechanical loading and deloading on human bones. Calcif Tissue Int, 1994, 55: 59-67. [Medline] [CrossRef]

20) Kim H, Noh H: The correlation between regional bone mineral status, body composition, and muscle strength of pre and postmenopausal women. Exerc Sci, 2005, 14: 347-358.

21) Düppe H, Gärdsell P, Johnell O, et al.: Bone mineral density, muscle strength and physical activity. A population-based study of 332 subjects aged $15-42$ years. Acta Orthop Scand, 1997, 68: 97-103. [Medline] [CrossRef]

22) Madsen KL, Adams WC, Van Loan MD: Effects of physical activity, body weight and composition, and muscular strength on bone density in young women. Med Sci Sports Exerc, 1998, 30: 114-120. [Medline] [CrossRef]

23) Chowdhury S, Ashrafunnessa, Khatun S, et al.: Comparison of bone mineral density between premenopausal and postmenopausal women in Bangladesh. Bangladesh Med Res Counc Bull, 2001, 27: 48-54. [Medline]

24) Namwongprom S, Ekmahachai M, Vilasdechanon N, et al.: Bone mineral density: correlation between the lumbar spine, proximal femur and Radius in northern Thai women. J Med Assoc Thai, 2011, 94: 725-731. [Medline]

25) Wolff J: The classic: on the inner architecture of bones and its importance for bone growth. 1870. Clin Orthop Relat Res, 2010, 468: 1056-1065. [Medline] [CrossRef]

26) Kemmler W, Weineck J, Kalender WA, et al.: The effect of habitual physical activity, non-athletic exercise, muscle strength, and VO2max on bone mineral density is rather low in early postmenopausal osteopenic women. J Musculoskelet Neuronal Interact, 2004, 4: 325-334. [Medline]

27) Sanchis-Moysi J, Dorado C, Vicente-Rodríguez G, et al.: Inter-arm asymmetry in bone mineral content and bone area in postmenopausal recreational tennis players. Maturitas, 2004, 48: 289-298. [Medline] [CrossRef]

28) Weiss M, Yogev R, Dolev E: Occupational sitting and low hip mineral density. Calcif Tissue Int, 1998, 62: 47-50. [Medline] [CrossRef]

29) Harris SS, Dawson-Hughes B: Weight, body composition, and bone density in postmenopausal women. Calcif Tissue Int, 1996, 59: 428-432. [Medline] [CrossRef]

30) Kroke A, Klipstein-Grobusch K, Bergmann MM, et al.: Influence of body composition on quantitative ultrasound parameters of the os calcis in a populationbased sample of pre- and postmenopausal women. Calcif Tissue Int, 2000, 66: 5-10. [Medline] [CrossRef] 